\title{
Visual Aura in Migraine: An Analysis of 165 Patients in a Tertiary Care Hospital in North India
}

\author{
${ }^{1}$ Department of Neurology, Dayanand Medical College and \\ Hospital, Ludhiana, Punjab, India \\ ${ }^{2}$ Department of Neurology, Guru Gobind Singh Medical College, \\ Faridkot, Punjab, India \\ ${ }^{3}$ School of Public Health and Preventive Medicine, Monash \\ University, Melbourne Victoria, Australia \\ ${ }^{4}$ Christian Medical College and Hospital, Ludhiana, Punjab, India
}

Monika Singla ${ }^{1}$ Sulena ${ }^{2}$ Richa Kale ${ }^{3}$ Jaisal Brar ${ }^{4}$ Sanskriti Bhardwaj ${ }^{4}$

\author{
Address for correspondence Monika Singla, DM (Neurology), 20-A, \\ Rajguru Nagar, Near MBD Mall, Ludhiana 141012, Punjab, India \\ (e-mail: drmonika78@yahoo.com).
}

J Neurosci Rural Pract 2021;12:273-280.

\begin{abstract}
Keywords

- migraine with aura

- visual aura

- scintillating scotoma

- transient ischemic attack
\end{abstract}

Background Migraine auras are transient neurological symptoms, usually lasting for approximately 5 to 30 minutes before the onset of migraine pain. Out of various types of auras, visual aura is the commonest and has variable manifestations, forming approximately $90 \%$ of auras. These visual auras may be of particular interest to the ophthalmologist as well as to the neurologist. We planned to conduct this study to look for the prevalence of visual aura in our population and make a descriptive analysis of the same.

Materials and Methods It was an observational, questionnaire-based cross-sectional study, enrolling all the consenting patients of migraine. Migraine was classified by International Classification of Headache Disorders (ICHD)-III $\beta$ version, Third edition of International Classification of Headache Disorders. Patients in whom aura was present, detailed profile of visual aura was made regarding its type, duration, relation with migraine as per its laterality, etc.

Observations and Results Out of 1,245 migraine patients, 165 (13.25\%) patients reported to have visual aura, 127 females and 38 males. Scintillating scotoma was the commonest type of visual aura, then zigzag lines, blurred vision, and tunnel vision. Majority of patients had aura between 5 and 35 minutes, none had more than 60 minutes. A total of 142 patients out of 165 had unilateral aura, out of which $64(38.78 \%)$ patients had aura ipsilateral to the side of headache, and 78 (47.27\%) patients had aura contralateral to the side of headache. Twenty-three (13.93\%) patients had bilateral aura.

Discussion The frequency of visual aura was found to be $13.25 \%$ in our study, which is high compared with previously published Indian data. We did a descriptive analysis of visual aura symptoms.

Conclusion Visual aura is the commonest type of aura, more frequent in females. Scintillating scotoma was found to be the commonest type of visual aura, followed by zigzag lines in study. Our study is unique of its type as its shows a descriptive visual analysis in a larger number of patients. published online March 3, 2021
DOI https://doi.org/ 10.1055/s-0040-1721624 ISSN $0976-3147$.
(C) 2021. Association for Helping Neurosurgical Sick People.

This is an open access article published by Thieme under the terms of the Creative Commons Attribution-NonDerivative-NonCommercial-License, permitting copying and reproduction so long as the original work is given appropriate credit. Contents may not be used for commercial purposes, or adapted, remixed, transformed or built upon. (https://creativecommons.org/licenses/by-nc-nd/4.0/). Thieme Medical and Scientific Publishers Pvt. Ltd. A-12, 2nd Floor, Sector 2, Noida-201301 UP, India 


\section{Introduction}

Migraine is a clinical syndrome of unknown etiology, leading to a variety of visual disturbances. Migraine with aura is an incapacitating myriad of transient neurological symptoms, often characterized by aura disturbances which can be visual and occasional sensory or dysphasic, preceding headache. Prevalence of migraine is variable as per different studies; it is $8 \%$ in general population as reported by Russel et al. ${ }^{1}$ Amongst all forms of aura disturbances the frequency of visual aura cases (98-99\%) is far more than sensory (36\%) and language (10\%) dysfunctions. ${ }^{2}$ In another study, migraine with typical visual aura was reported in more than $30 \%$ of their attacks, white spots, zigzag lines, flashing lights, and scotoma being the most frequently prevalent visual aura symptoms. ${ }^{3}$ Though visual aura symptoms are complex visual disturbances and mostly multifaceted, they have a marked heterogeneity without any pathophysiological explanation. ${ }^{4}$ The main characteristics of visual aura may include exclusively visual aura with and without headache, acute onset (sudden) visual aura, sensory and motor auras, unilateral or bilateral visual auras followed by unilateral or bilateral headache. A typical visual aura can initiate as a flickering, unilateral, uncolored squiggly line. It may start in the center with gradual spread toward the periphery. ${ }^{5}$ The progression of visual aura across the visual field is slow, i.e., $>4$ minutes, with a gradual return to normalcy within 20 minutes to an hour, contrary to cerebral ischemia which is usually sudden in onset. In contrast to seizures the progression from positive phenomenon (zigzag vision, shimmering, tingling, or scintillations) to negative symptoms (scotoma) is paced and gradual in migraine with aura and sometimes in form of complex infrequent perceptions like tunnel vision, hallucinations, etc. ${ }^{6}$ As per International Classification of Headache Disorders (ICHD)-3 $\beta$ version, the diagnostic criteria include at least two attacks with one or more fully reversible aura symptoms like visual, speech, sensory, brainstem, motor, or retinal, with gradual spread over $\geq 5$ minutes, lasting between 5 and 60 minutes, occurring in succession. One aura symptom may be unilateral, the aura is usually followed by headache mostly on the opposite side. ${ }^{7,8}$ The marked inter and intrapatient variability amongst various forms of aura suggests varied and distinct underlying anatomical dysfunctions. ${ }^{9}$ Migraine visual aura can be seen independently without headache in approximately $3 \%$ of the general population..$^{10}$ Visual disturbances of migraine generally last less than an hour, but sometimes may last for days to even months. ${ }^{11,12}$ As per literature, migraine with visual aura has increased risk of vascular events like stroke, transient ischemic attacks, myocardial infarction, atrial fibrillation as compared with patients of migraine without aura. ${ }^{13-15}$

Despite being thoroughly studied, descriptive analysis of visual aura with migraine has not been reported much. Therefore, we planned to conduct a study in our patients of migraine to study the presence of visual aura and make a comprehensive list of all the visual symptoms present in them.

\section{Methods}

The study was conducted in a tertiary care hospital, the South-Western corner of Punjab, in North India. This hospital mainly caters to rural population. We screened all the patients who presented to our neurology outpatient department with complaints of headache. All patients who consented to take part and fulfilled ICHD-III $\beta$ version and 2013 criteria for migraine were enrolled in the study. Study was conducted between August 2016 and January 2018. Institutional ethics clearance was taken for the same. Patients with one-time headache, secondary headaches, and tension headache were excluded from the study. We could not identify any patient with trigeminal autonomic cephalgias. Out of 1,586 patients, 1,245 patients of migraine were included in the study, out of which 937 were female patients and 308 were males. A structured questionnaire was applied to all the participants. A medical student was trained for the same; he was also trained regarding questionnaire related with aura and types of aura. Questionnaire included four sections, first section was related with demographic factors including age, sex, marital status, occupation, and education. Another section dealt with questions related with first contact of patient regarding diagnosis, who diagnosed their first headache, a general physician, a neurologist, other or they did not contact anyone? Third section had questions related with severity of headache, description and location of headache, along with accompanying features like photophobia, phonophobia, nausea, vomiting, numbness, ringing sensation, dizziness etc. Then in the last section, questions regarding light sensitivity, triggers of migraine, and various co-morbidities were asked. MIDAS score was also applied for all patients to assess migraine-related disability. A necessary clinical examination was performed on all the patients. To all the patients of migraine, detailed questions related with aura, types of aura, duration of aura were asked. For visual aura, a questionnaire was applied regarding type of visual symptoms, positive or negative symptoms. Patients were enquired regarding duration of headache, relation of aura with headache episode, number and types of auras or overlap of auras if they had. Patients were requested to draw the aura on a paper from their memory which they experienced during the attacks. In case of any doubt about aura symptoms, it was confirmed by the treating neurologist. Clinical examination was performed by the neurologist on all the patients, especially in patients with migraine with aura for any focal deficits. Fundus examination was performed by ophthalmologist in all the patients with visual aura, especially with scotomas. Computed tomography of head was performed in all the patients with visual aura. Magnetic resonance imaging (MRI) of brain was done in selected patients where there were doubtful symptoms. Though MRI brain with magnetic resonance angiography is preferred in migraine with aura attacks, it was not possible in our hospital as there was huge rush in hospital for neuroimaging of the brain so it was not possible to get MRI brain on the same day in most of the patients. 


\section{Statistical Analysis}

SPSS Statistics v25, SAS Studio 3.7 and Excel (Office 365) were primarily used for analyzing data. Exploratory data analysis was performed on explanatory variables (such as demographic variables). Distribution analysis was conducted for independent variables and the data was visualized using flowcharts, tables, and Venn diagrams.

\section{Observations and Results}

Out of 1,586 patients of headache, 1,518 consented to take part in the study. After excluding 273 nonmigraine headache patients, 1,245 patients were enrolled for the study. Out of 1,245 patients, 180 (14.46\%) patients reported to have aura (-Fig. 1, flowchart). $14.46 \%$ patients had migraine with aura, with visual aura being the commonest out of all auras with frequency of $13.25 \%$. Therefore 165 (91.66\% of all auras) patients reported to have visual aura, 127 being female patients and 38 males. Baseline characteristics of patients of migraine with aura and migraine without visual aura have been described in detail in - Table 1 . In both the groups, females outnumbered males and the most common affected age group was 25 to 44 years in both the groups. On comparing both the groups, migraine without visual aura and migraine with visual aura, there was no statistical difference in terms of gender, age range, marital status, education, type of pain, pain intensity in both the groups. Mean age of migraine without aura group was 36.66 years $( \pm 13.42)$, with confidence interval of 35.85 to 37.47 and $p<$ 0.001 and in migraine with aura group 37.91 years $( \pm 13.31)$, with confidence interval of 35.85 to 39.98 and $p<0.001$. Age being exposure variable shows significant impact on disease outcome in both the groups. Regarding duration of pain attack, 1,106 (88.83\%) patients had attacks lasting less

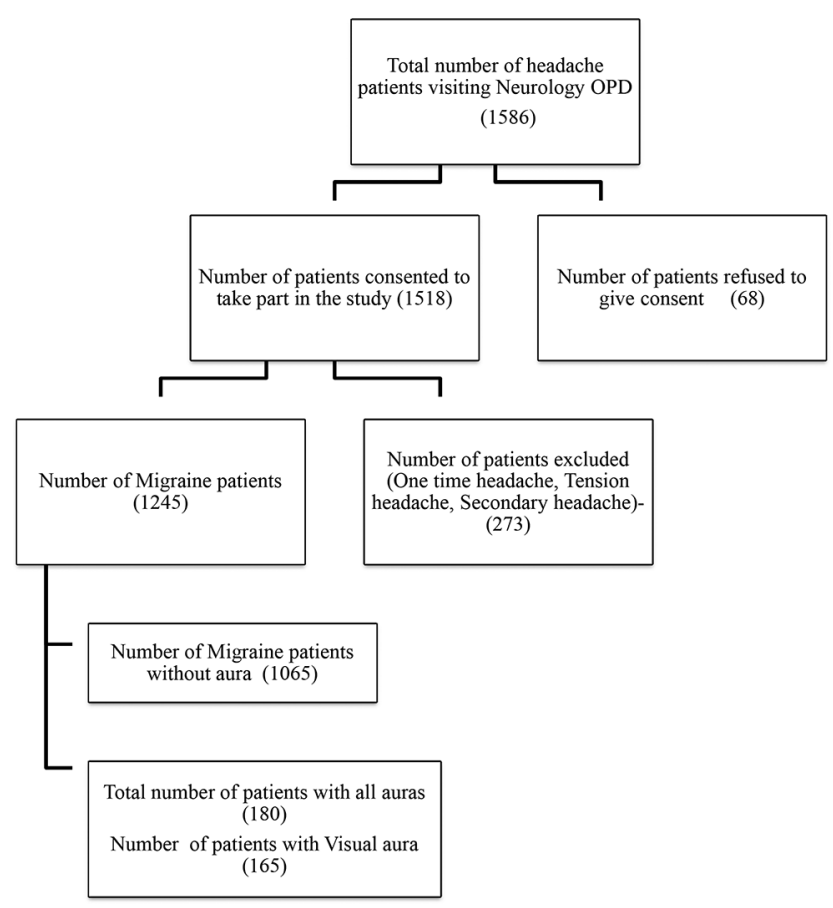

Fig. 1 Patient flowchart. than 24 hours. Only 52 patients $(4.17 \%)$ had pain lasting for more than 24 hours, out of these, six patients were found to have medication overuse related to headache as they were consuming regular analgesics. The number of headache attacks varied from two to 17 per month in migraine without aura group and from one to five attacks in migraine with aura group. On comparing comorbidities, depression and syncope were found more commonly in migraine with aura group and it was statistically significant $(p<0.05)$, though anxiety was found more in migraine without aura group $(p<0.05)$.

We applied MIDAS questionnaire to all patients with migraine with aura to access the disease-related disability and its impact on their quality of lives in the previous 3 months. About 87 patients (52.73\%) had mild disability, 23 patients (13.93) had little or no disability, 33 patients (20\%) had moderate disability, and 22 patients (13.33\%) had severe disability. Most common accompanying feature found in our migraine with visual aura patients was fatigability, found in 77 patients (46.67\%), followed by nausea/vomiting in 52 patients (31.52\%), then photophobia in 50 patients (30.3\%), numbness, vertiginous sensation, and tingling in the remaining patients. Common trigger factors for migraine attacks were stress, noise, exertion, sleep disturbances, smell, and hormonal factors.

On analyzing the types of auras, 165 patients were found to have visual aura, 37 patients (20.5\%) complained of slurring of the speech preceding headache, numbness as aura was seen in 12 (6.7\%) patients, and weakness (hemiplegia) was seen in only two patients $(1.1 \%)$ (-Table 2 ). Venn diagram (-Fig. 2A, B) shows overlap of various types of auras in females and males. On doing gender wise comparison amongst aura types, there was no statistically significant difference found in both the genders with regard to various aura types. A total of 105 (63.63\%) patients had aura preceding headache, 24 (14.54\%) patients had headache preceding aura. Patients with visual aura did not have headaches during all the episodes, 36 (21.8\%) patients were found to have only aura without any headache. The duration of aura was variable between 5 and 35 minutes. No patient had any persistent aura. One hundred and forty-two patients had unilateral aura, out of which 64 (38.78\%) patients had aura ipsilateral to the side of headache, 78 (47.27\%) patients had aura contralateral to the side of headache. Twenty-three (13.93\%) patients had bilateral aura (-Table 3). Twenty-one percent of the patients had more than one type of aura and 5\% had even two or three types of aura. Amongst the patients with visual aura also, 23\% of the patients had overlap of various types of auras. Venn diagram shows overlap of four most common visual auras (-Fig. 3). Scintillating scotoma was the commonest type of aura present in $39.39 \%$ of the patients; next common was zigzag lines and blurring of vision. Details of various types of auras are mentioned in - Table 4. - Fig. 4 (A-D) shows illustrations of visual aura of four patients felt during the migraine attack and drawn on a paper during their outdoor patient department visits. 
Table 1 Baseline characteristics of patients with migraine without and with visual aura

\begin{tabular}{|c|c|c|c|c|c|c|c|}
\hline & \multirow{2}{*}{$\begin{array}{l}\text { Migraine without } \\
\text { visual aura } \\
\text { Total } N(\%) \\
\end{array}$} & \multirow[t]{2}{*}{$\begin{array}{l}\text { Female } N \\
(\%)\end{array}$} & \multirow[t]{2}{*}{ Male $N(\%)$} & \multirow{2}{*}{$\begin{array}{l}\text { Migraine with } \\
\text { visual aura } \\
\text { Total } N(\%)\end{array}$} & \multirow[t]{2}{*}{$\begin{array}{l}\text { Female } N \\
(\%)\end{array}$} & \multirow[t]{2}{*}{ Male N (\%) } & \\
\hline & & & & & & & \\
\hline Gender & $1,065(100 \%)$ & 799 (75.02\%) & $266(24.98 \%)$ & $165(100 \%)$ & 127 (76.97\%) & $38(23.03 \%)$ & 0.589 \\
\hline \multirow[t]{3}{*}{ Age vitals } & Mean age & & & Mean age & & & \\
\hline & $\begin{array}{l}36.66 \text { y }( \pm 13.42) \\
p<0.001\end{array}$ & & & $\begin{array}{l}37.91 \text { y }( \pm 13.31) \\
p<0.001\end{array}$ & & & \\
\hline & Total N (\%) & Female $N(\%)$ & Male $N(\%)$ & Total N (\%) & Female $N(\%)$ & Male N (\%) & \\
\hline \multicolumn{8}{|l|}{ Age } \\
\hline Up to $24 \mathrm{y}$ & 187 (17.56\%) & 112 (59.89\%) & 75 (40.11\%) & $21(12.73 \%)$ & $14(66.67 \%)$ & $7(33.33 \%)$ & 0.246 \\
\hline $25-44$ y & 549 (51.55\%) & 437 (79.60\%) & $112(20.40 \%)$ & 95 (57.58\%) & $76(80.00 \%)$ & 19 (20.00\%) & \\
\hline $45-64 y$ & $287(26.95 \%)$ & 227 (79.09\%) & $60(20.91 \%)$ & $40(24.24 \%)$ & $31(77.50 \%)$ & $9(22.50 \%)$ & \\
\hline$>65 y$ & $42(3.94 \%)$ & $23(54.76 \%)$ & $19(45.24 \%)$ & $9(5.45 \%)$ & $6(66.67 \%)$ & $3(33.33 \%)$ & \\
\hline Marital status & & & & $(0.00 \%)$ & & & \\
\hline Married & $896(84.13 \%)$ & 707 (78.91\%) & $189(21.09 \%)$ & $143(86.67 \%)$ & $114(79.72 \%)$ & $29(20.28 \%)$ & 0.403 \\
\hline Unmarried & $169(15.87 \%)$ & $92(54.44 \%)$ & 77 (45.56\%) & $22(13.33 \%)$ & $13(59.09 \%)$ & $9(40.91 \%)$ & \\
\hline \multicolumn{8}{|l|}{ Education } \\
\hline Undergraduates & $819(76.90 \%)$ & $588(71.79 \%)$ & $231(28.21 \%)$ & $133(80.61 \%)$ & $99(74.44 \%)$ & $34(25.56 \%)$ & 0.171 \\
\hline Post-graduation & $54(5.07 \%)$ & $46(85.19 \%)$ & $8(14.81 \%)$ & $3(1.82 \%)$ & $3(100.00 \%)$ & $0(0.00 \%)$ & \\
\hline Illiterate & $192(18.03 \%)$ & 165 (85.94\%) & $27(14.06 \%)$ & $29(17.58 \%)$ & $25(86.21 \%)$ & $4(13.79 \%)$ & \\
\hline Pain type & Total instances 1,314 & & & Total Instances 209 & & & \\
\hline Aching & $280(21.31 \%)$ & $200(71.43 \%)$ & $80(28.57 \%)$ & $43(20.57 \%)$ & $29(67.44 \%)$ & $14(32.56 \%)$ & 0.950 \\
\hline $\begin{array}{l}\text { Throbbing/ } \\
\text { pulsating }\end{array}$ & $280(21.31 \%)$ & $217(77.50 \%)$ & $63(22.50 \%)$ & 40 (19.14\%) & $34(85.00 \%)$ & $6(15.00 \%)$ & 0.576 \\
\hline Sharp/lancing & $446(33.94 \%)$ & $332(74.44 \%)$ & $114(25.56 \%)$ & 67 (32.06\%) & 55 (82.09\%) & $12(17.91 \%)$ & 0.757 \\
\hline Pressure/squeeze & $308(23.44 \%)$ & $231(75.00 \%)$ & $77(25.00 \%)$ & $59(28.23 \%)$ & 46 (77.97\%) & $13(22.03 \%)$ & 0.741 \\
\hline $\begin{array}{l}\text { Pain intensity in } \\
\text { last } 12 \mathrm{mo}\end{array}$ & Total instances 1,080 & & & Total Instances 165 & & & \\
\hline Mild & $130(12.04 \%)$ & $85(65.38 \%)$ & $45(34.62 \%)$ & $13(07.88 \%)$ & $5(38.46 \%)$ & $8(61.54 \%)$ & 0.261 \\
\hline Moderate & 338 (31.30\%) & 240 (71.01\%) & 98 (28.99\%) & $51(30.91 \%)$ & $36(70.59 \%)$ & 15 (29.41\%) & \\
\hline Severe & $612(56.67 \%)$ & 484 (79.08\%) & $128(20.92 \%)$ & $101(61.21 \%)$ & $86(85.15 \%)$ & 15 (14.85\%) & \\
\hline Comorbidities & Total instances 287 & & & Total Instances 72 & & & \\
\hline Depression & 49 (17.07\%) & 31 (63.27\%) & $18(36.73 \%)$ & $18(25 \%)$ & $12(85.71 \%)$ & $2(14.29 \%)$ & 0.0008 \\
\hline Syncope & 63 (21.95\%) & $42(66.67 \%)$ & $21(33.33 \%)$ & 21 (29.17\%) & $10(66.67 \%)$ & $5(33.33 \%)$ & 0.001 \\
\hline Anxiety & 160 (55.75\%) & $116(72.50 \%)$ & $44(27.50 \%)$ & 44 (61.11\%) & $23(63.89 \%)$ & $13(36.11 \%)$ & 0.001 \\
\hline Others & $15(5.23 \%)$ & $12(80.00 \%)$ & $3(20.00 \%)$ & $3(4.16 \%)$ & $5(71.43 \%)$ & $2(28.57 \%)$ & 0.683 \\
\hline \multicolumn{8}{|l|}{ Medications } \\
\hline Beta blockers & $140(13.14)$ & $84(10.51 \%)$ & $56(21.05 \%)$ & 65 (39.39\%) & 43 (33.85\%) & 22 (57.89\%) & \\
\hline $\begin{array}{l}\text { Tricyclic } \\
\text { antidepressants }\end{array}$ & $88(8.26 \%)$ & $53(6.63 \%)$ & $35(13.16 \%)$ & $39(23.63 \%)$ & 35 (27.56\%) & $4(10.53 \%)$ & \\
\hline Topiramate & $35(3.28)$ & $30(3.75 \%)$ & $5(1.88 \%)$ & $13(7.88)$ & $10(7.87 \%)$ & $3(7.89 \%)$ & \\
\hline Flunarizine & $33(31 \%)$ & $23(2.87 \%)$ & $10(3.76 \%)$ & $9(5.45 \%)$ & $8(6.3 \%)$ & $2(5.26 \%)$ & \\
\hline Analgesics & $110(10.33 \%)$ & $88(11.01 \%)$ & $22(8.27 \%)$ & $12(7.27 \%)$ & $9(7.09 \%)$ & $2(5.26 \%)$ & \\
\hline No treatment & 659 (61.88\%) & $521(65.2 \%)$ & 138 (51.87\%) & 27 (16.36\%) & $22(17.32 \%)$ & $5(13.16 \%)$ & \\
\hline
\end{tabular}


Table 2 Aura distribution by gender

\begin{tabular}{|l|l|l|l|l|}
\hline Aura type & Total $N(\%)$ & Female $N(\%)$ & Male $N(\%)$ & $p$-Value \\
\hline Visual aura & $165(100 \%)$ & $127(76.97 \%)$ & $38(23.03 \%)$ & 0.671 \\
\hline Slurring of speech & $37(22.42 \%)$ & $25(67.57 \%)$ & $12(32.43 \%)$ & \\
\hline Weakness & $2(1.21 \%)$ & $2(100.00 \%$ & $0(0.00 \%)$ & \\
\hline Numbness & $12(7.27 \%)$ & $9(75.00 \%)$ & $3(25.00 \%)$ & \\
\hline
\end{tabular}
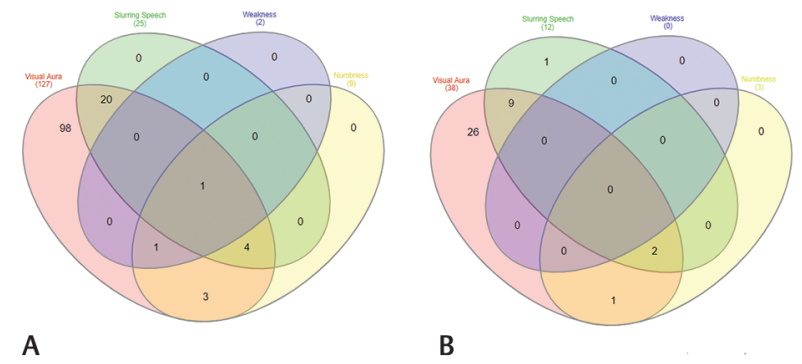

Fig. 2 (A) Venn diagram showing overlap of four aura types found in our population, visual aura, slurring of speech, weakness, and numbness in female patients and (B) in male patients.

Table 3 Visual aura details (in terms of number, duration, laterality, and relation with headache)

\begin{tabular}{|c|l|l|}
\hline & $\begin{array}{l}\text { Number } \\
\text { of } \\
\text { patients }\end{array}$ & Percentage \\
\hline Number of visual aura & 127 & 76.97 \\
\hline Females & 38 & 23.03 \\
\hline Males & & \\
\hline Duration of aura & 105 & 63.63 \\
\hline $5-30$ min & 60 & 36.36 \\
\hline $31-60$ min & 0 & 0 \\
\hline 60 min & & \\
\hline Unilateral aura & 64 & 38.78 \\
\hline Ipsilateral & 78 & 47.27 \\
\hline Contralateral & 23 & 13.93 \\
\hline Bilateral aura & 105 & 63.63 \\
\hline Aura preceding headache & 36 & 21.8 \\
\hline Aura without headache & 24 & 14.54 \\
\hline Headache preceding aura & 23 & 13.93 \\
\hline $\begin{array}{l}\text { Number of patients had headache } \\
\text { episodes without aura }\end{array}$ & & \\
\hline
\end{tabular}

\section{Discussion}

Our study evaluated the characteristics of aura in migraine in detail. All patients were diagnosed with ICHD-III $\beta$ version 2013 criteria. All patients underwent a structured questionnaire including multiple sections pertaining to migraine characteristics and migraine with aura. Our study was conducted over a large sample of patients. Ours was a hospital-based cross-sectional study; patients were questioned regarding their aura

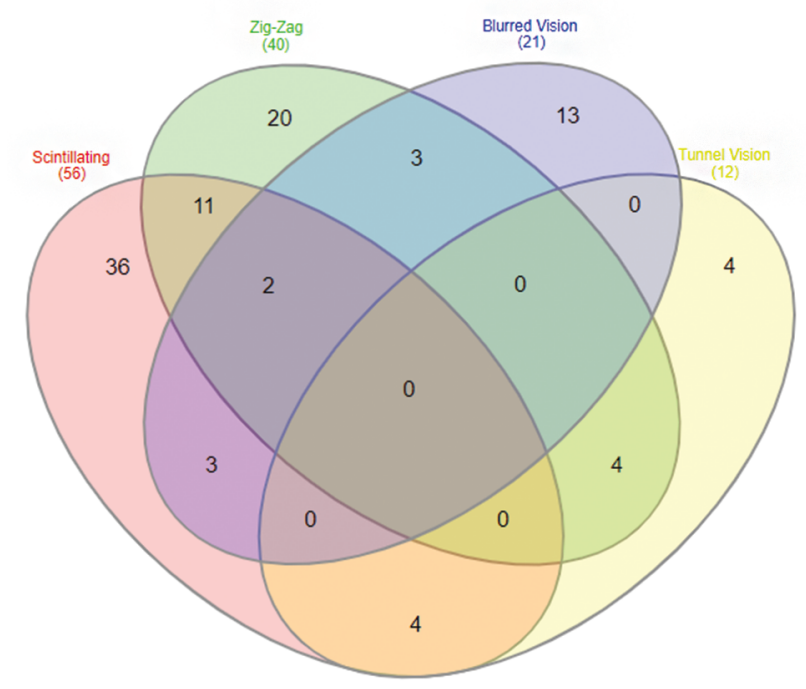

Fig. 3 Venn diagram showing overlap of four commonest types of visual auras found in our study population, i.e., scintillating scotoma, zigzag lines, blurred vision, and tunnel vision.

Table 4 Detailed analysis of types of visual aura

\begin{tabular}{|l|l|l|}
\hline & $\begin{array}{l}\text { Number of } \\
\text { patients }\end{array}$ & Percentage \\
\hline Scintillating scotoma & 56 & 33.93 \\
\hline Zigzag lines & 40 & 24.24 \\
\hline Blurred vision & 21 & 12.72 \\
\hline Tunnel vision & 12 & 7.27 \\
\hline Flashes of bright light & 19 & 11.51 \\
\hline Blind spots & 19 & 1.51 \\
\hline Macropsia & 14 & 8.48 \\
\hline Micropsia & 13 & 7.87 \\
\hline Complex hallucinations & 5 & 3.03 \\
\hline Flickering lights & 15 & 9.09 \\
\hline Visual snow & 7 & 4.24 \\
\hline Things look farther than they are & 9 & 5.45 \\
\hline White spots & 5 & 3.03 \\
\hline Hemianopsia & 3 & 1.81 \\
\hline Like a mosaic & 2 & 1.21 \\
\hline Crescent shaped & 2 & 1.21 \\
\hline Colored lines & 1 & 0.60 \\
\hline & & \\
\hline
\end{tabular}



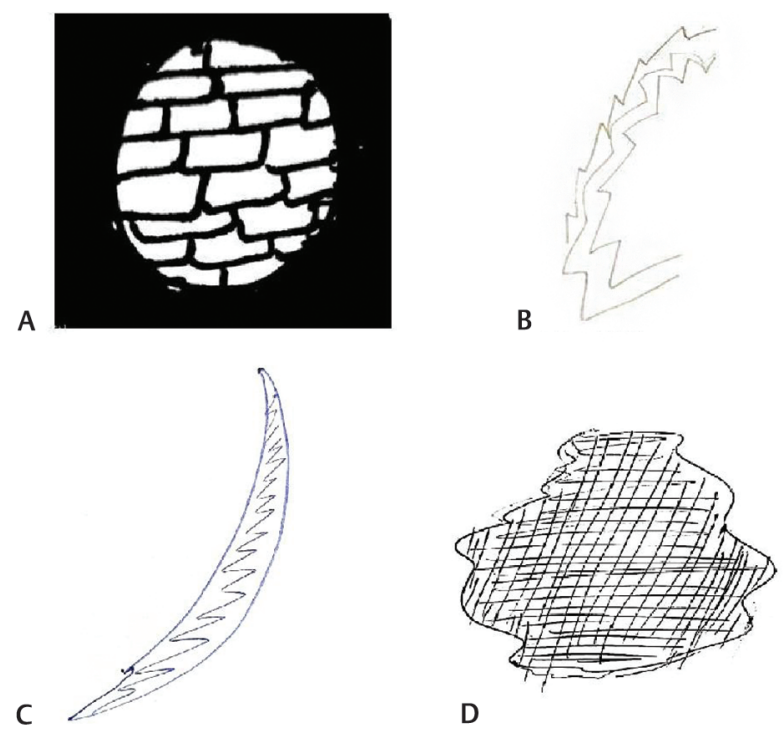

Fig. 4 (A) Case Vignette 1-picture depicting aura of a patient which he experienced while he was at his construction site. He started seeing only part of the wall in the center and as if other part of wall disappeared suggestive of tunnel vision followed by headache. (B) Case Vignette 2-picture depicting aura of a patient while working in her office, felt wavy lines suggestive of zigzag aura. (C) Case Vignette 3-suggestive of scintillating scotoma experienced by a patient preceding a migraine attack as visual aura while she was teaching her students, she could not see her class properly, she was seeing moving shining arc-shaped scotoma. (D) Case Vignette 4-a 35-year-old female suffered from an episode while she was teaching her students in school. She started seeing a black spot in her vision, which lasted for few minutes, followed by severe unilateral pulsatile headache. It lasted for about 5 hours and then settled down.

experience. In our study frequency of visual aura was found to be $13.25 \%$ which is high compared with previously reported Indian studies. ${ }^{16}$ The explanation for the high prevalence may be that our study was conducted in a tertiary care hospital and patients with aura symptoms are more likely to report to the hospital, considering it to be serious. In our study visual aura was found to be the commonest. Our findings were comparable to the study narrated by Evans, where visual aura (99\%) outnumbered sensory (54\%) and aphasic (32\%) auras. ${ }^{6}$

Twenty-four (14.54\%) patients had headache preceding aura and 36 (21.8\%) patients were found to have only aura without any headache in our study. Majority of the aura patients, i.e., $63.63 \%$ patients had aura preceding headache, which is comparable to data reported by Queiroz et $\mathrm{al}^{17}$ in $57 \%$, Kelman ${ }^{18}$ in $67.4 \%$, and Russell and Olesen ${ }^{5}$ in $92 \%$, had aura exclusively before headache. The duration of the visual auras in our study was 5 to 30 minutes seen in $63.63 \%$ of the patients which is quite similar to findings reported by Queiroz et $\mathrm{al}^{17}(59 \%)$, Bana and Graham ${ }^{19}$ (64.7\%), Kelman ${ }^{18}$ (63\%), Russell and Olesen ${ }^{5}$ (69\%), and Manzoni et $\mathrm{al}^{20}$ (75.6\%), Cologno et $\mathrm{al}^{21}(65.4 \%)$ where the reported duration of aura was 5 to 30 minutes.

In our study, only 23 (13.93\%) patients had bilateral aura. Unilateral auras are reported in majority, i.e., 142 patients. This finding is also comparable with the study done by Queiroz et $\mathrm{al}^{22}$ as they reported in unilaterality in 76 patients out of 122 patients.
Twenty-one percent of the patients had more than one type of aura and $5 \%$ had even two or three types of aura. Amongst the patients with visual aura also, $23 \%$ of the patients had overlap of various types of auras. Scintillating scotoma was the commonest type of aura present in 33.93\% of the patients; next common was zigzag lines and blurring of vision. Queiroz et $\mathrm{a}^{22}$ reported "blurred/foggy vision" as the most common symptom and "small bright dots" as the second most frequent visual hallucination in their study. This is similar to Queiroz et $\mathrm{al}^{17}$ as they found this in $42 \%$ of the patients. Eriksen et $\mathrm{a}^{23}$ reported zigzag lines in $58 \%$ of the patients and Russell and Olesen ${ }^{5}$ patients reported these lines in $81 \%$ of the patients. We compared our findings with previously published data in view of types of aura, gender preference, laterality, and colored/uncolored hallucinations ${ }^{23}$ (- Table 5).

Regarding the pathophysiology and blood flow studies related to laterality of aura and headache, Olesen et $\mathrm{a}^{24}$ had studied headache and aura laterality. They studied regional cerebral blood flow (rCBF) and found information about laterality. They have reported that $\mathrm{rCBF}$ changes are virtually unilateral. In areas of low blood flow, there is origin of aura symptoms. Abnormalities in $\mathrm{rCBF}$ unilaterally were significantly associated with ipsilateral or bilateral headache. Aura that is usually unilateral is significantly associated with contralateral or bilateral headache. Regarding laterality of aura and $\mathrm{rCBF}$ abnormalities, they reported these to be contralateral to each other.

We planned to do the comprehensive analysis of visual aura in our study population. Migraine aura itself is a risk factor for cerebrovascular diseases like stroke and heart diseases including myocardial infarction and atrial fibrillation. ${ }^{14,25,26}$ Moreover migraine is more common in females in young age and use of oral contraceptives leads to 13 times increased risk of stroke and thromboembolism in patients with migraine with aura. ${ }^{27,28}$ Therefore it is very important to understand aura and its types in a better way. This will help in planning future studies. Aura usually has gradual onset suggestive of cortical spreading depression as the pathophysiology, therefore it can be differentiated from ischemia, inflammation, and compression. .9,30 $^{2}$ Panayiotopoulos has stated regarding differentiating occipital seizures from visual auras on the basis of color of visual hallucinations. Auras in seizures are usually circular/spherical in forms and multicolored, and the auras of migraine are blackand-white, with linear/zigzag lines. ${ }^{31,32}$ Russel et al reported colored auras in 13 attacks (24\%) out of 54 aura attacks in 20 patients. ${ }^{33}$ Therefore, it is very important to correctly diagnose these visual symptoms as aura and differentiate them from transient ischemic attacks, stroke, and seizure. Our study has this limitation as we did not ask regarding colors of auras and family history. We also did not do MRI of the brain with magnetic resonance angiography in our patients during attacks of aura to differentiate from stroke or transient ischemic attack. Another limitation of our study was that patient's responses were not recorded during the aura attacks; they responded to our questions from their memory, so there can be a recall bias in our study.

Our study is unique in some aspects that we conducted this observational, cross-sectional study on a larger population and we could find a large number of patients with visual 


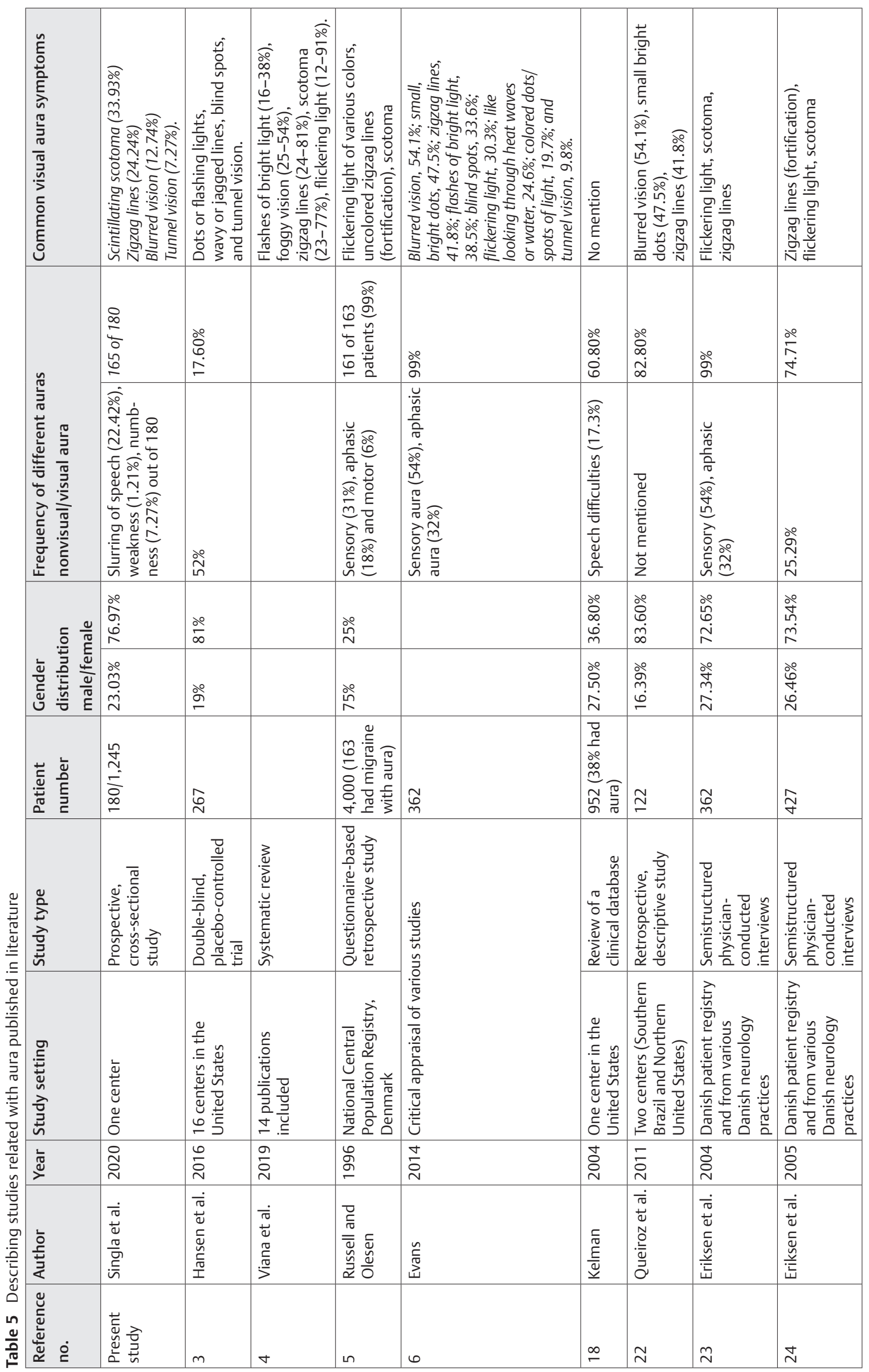


aura in our population as compared with previously published studies. Then we tried to explain the various clinical aspects of visual aura in detail. This kind of descriptive analysis of visual aura was not performed frequently. As migraine with aura is much more common in females as compared with males, awareness can be created in females of reproductive age group regarding the use of oral contraceptives and its increased risk associated with stroke.

\section{Conclusion}

Visual aura was found to be the commonest in our study, in $13.25 \%$ of the patients. We gave a descriptive analysis of various types of visual aura in our study. Visual auras were heterogenous in our study. The maximum duration of aura was found to be 35 minutes. Most of the auras were unilateral. There was no fixed relationship with headache duration and side of headache with aura. Out of various types of aura, scintillating scotoma, zigzag lines, tunnel vision, and blurred vision were found to be the commonest in our study.

\section{Note}

The study primarily carried out at Guru Gobind Singh Medical College, Faridkot

\section{Conflict of Interest}

None declared.

\section{References}

1 Russell MB, Rasmussen BK, Thorvaldsen P, Olesen J. Prevalence and sex-ratio of the subtypes of migraine. Int $\mathrm{J}$ Epidemiol 1995;24(3):612-618

2 Viana M, Sances G, Linde M, et al. Clinical features of migraine aura: results from a prospective diary-aided study. Cephalalgia 2017;37(10):979-989

3 Hansen JM, Goadsby PJ, Charles AC. Variability of clinical features in attacks of migraine with aura. Cephalalgia 2016;36(3):216-224

4 Viana M, Tronvik EA, Do TP, Zecca C, Hougaard A. Clinical features of visual migraine aura: a systematic review. J Headache Pain 2019;20(1):64-70

5 Russell MB, Olesen J. A nosographic analysis of the migraine aura in a general population. Brain 1996;119(Pt 2):355-361

6 Evans R, The Clinical Features of Migraine with and without Aura CRST; 2014 51-60

7 Olesen J, Dodick DW, Ducros A, Evers S, First MB, Goadsby PJ, et al. The international classification of headache disorders, 3rd edition (ICHD-3). Cephalalgia 2013;33:629-808

8 Agostoni E, Aliprandi A. The complications of migraine with aura. Neurol Sci 2006;27(suppl 2):S91-S95

9 Hadjikhani N, Vincent M. Neuroimaging clues of migraine aura. J Headache Pain 2019;20(1):32

10 Khessali H, Mojadidi MK, Gevorgyan R, Levinson R, Tobis J. The effect of patent foramen ovale closure on visual aura without headache or typical aura with migraine headache. JACC Cardiovasc Interv 2012;5(6):682-687

11 Liu GT, Schatz NJ, Galetta SL, Volpe NJ, Skobieranda F, Kosmorsky GS. Persistent positive visual phenomena in migraine. Neurology 1995;45(4):664-668

12 Lim J, Jo KD, Lee MK, Jang W. Persistent negative visual aura in migraine without headache: a case report. J Med Case Reports 2014;8(1):61
13 Stang PE, Carson AP, Rose KM, et al. Headache, cerebrovascular symptoms, and stroke: the Atherosclerosis Risk in Communities Study. Neurology 2005;64(9):1573-1577

14 Sen S, Androulakis XM, Duda V, et al. Migraine with visual aura is a risk factor for incident atrial fibrillation: a cohort study. Neurology 2018;91(24):e2202-e2210

15 Adelborg K, Szépligeti SK, Holland-Bill L, et al. Migraine and risk of cardiovascular diseases: Danish population based matched cohort study. BMJ 2018;360:k96

16 Ravishankar K. Headache pattern in India-a headache clinic analysis of 1000 patients. Cephalalgia 1997;17:316-317

17 Queiroz LP, Rapoport AM, Weeks RE, Sheftell FD, Siegel SE, Baskin SM. Characteristics of migraine visual aura. Headache 1997;37(3):137-141

18 Kelman L. The aura: a tertiary care study of 952 migraine patients. Cephalalgia 2004;24(9):728-734

19 Bana DS, Graham JR. Observations on prodromes of classic migraine in a headache clinic population. Headache 1986;26(5):216-219

20 Manzoni GC, Farina S, Lanfranchi M, Solari A. Classic migraine-clinical findings in 164 patients. Eur Neurol 1985;24(3):163-169

21 Cologno D, Torelli P, Manzoni GC. A prospective study of the headache phase in 32 migraine with aura patients. Cephalalgia 2002;22(6):411-415

22 Queiroz LP, Friedman DI, Rapoport AM, Purdy RA. Characteristics of migraine visual aura in Southern Brazil and Northern USA. Cephalalgia 2011;31(16):1652-1658

23 Eriksen MK, Thomsen LL, Olesen J. The visual aura rating scale (VARS) for migraine aura diagnosis. Cephalalgia 2005;25(10):801-810

24 Olesen J. Cerebral and extracranial circulatory disturbances in migraine: pathophysiological implications. Cerebrovasc Brain Metab Rev 1991;3(1):1-28

25 Spector JT, Kahn SR, Jones MR, Jayakumar M, Dalal D, Nazarian S. Migraine headache and ischemic stroke risk: an updated meta-analysis. Am J Med 2010;123(7):612-624

26 Mahmoud AN, Mentias A, Elgendy AY, et al. Migraine and the risk of cardiovascular and cerebrovascular events: a meta-analysis of 16 cohort studies including 1152407 subjects. BMJ Open 2018;8(3):e020498

27 Tzourio C, Tehindrazanarivelo A, Iglésias S, et al. Case-control study of migraine and risk of ischaemic stroke in young women. BMJ 1995;310(6983):830-833

28 Lipton RB, Bigal ME, Diamond M, Freitag F, Reed ML, Stewart WF; AMPP Advisory Group. Migraine prevalence, disease burden, and the need for preventive therapy. Neurology 2007;68(5):343-349

29 Lauritzen M, Dreier JP, Fabricius M, Hartings JA, Graf R, Strong AJ. Clinical relevance of cortical spreading depression in neurological disorders: migraine, malignant stroke, subarachnoid and intracranial hemorrhage, and traumatic brain injury. J Cereb Blood Flow Metab 2011;31(1):17-35

30 Lauritzen M. Pathophysiology of the migraine aura. The spreading depression theory. Brain 1994;117(Pt 1) :199-210

31 Panayiotopoulos CP. Elementary visual hallucinations in migraine and epilepsy. J Neurol Neurosurg Psychiatry 1994;57(11):1371-1374

32 Panayiotopoulos CP. Elementary visual hallucinations, blindness, and headache in idiopathic occipital epilepsy: differentiation from migraine. J Neurol Neurosurg Psychiatry 1999;66(4):536-540

33 Russell MB, Iversen HK, Olesen J. Improved description of the migraine aura by a diagnostic aura diary. Cephalalgia 1994;14(2):107-117 